\title{
Choline status and neurodevelopmental outcomes at 5 years of age in the Seychelles Child Development Nutrition Study
}

\author{
J. J. Strain ${ }^{1 *}$, Emeir M. McSorley ${ }^{1}$, Edwin van Wijngaarden ${ }^{2}$, Roni W. Kobrosly ${ }^{2}$, Maxine P. Bonham ${ }^{3}$, \\ Maria S. Mulhern ${ }^{1}$, Alison J. McAfee ${ }^{1}$, Philip W. Davidson ${ }^{2}$, Conrad F. Shamlaye ${ }^{4}$, Juliette Henderson ${ }^{4}$, \\ Gene E. Watson ${ }^{2}$, Sally W. Thurston ${ }^{2}$, Julie M. W. Wallace ${ }^{1}$, Per M. Ueland ${ }^{5}$ and Gary J. Myers ${ }^{2}$ \\ ${ }^{1}$ Northern Ireland Centre for Food and Health (NICHE), School of Biomedical Sciences, University of Ulster, Coleraine, \\ Northern Ireland, BT52 1SA, UK \\ ${ }^{2}$ School of Medicine and Dentistry, University of Rochester, Rochester, NY, USA \\ ${ }^{3}$ Department of Nutrition and Dietetics, Monash University, Victoria, Australia \\ ${ }^{4}$ Child Development Centre, Ministry of Health, Mahé, Republic of Seychelles \\ ${ }^{5}$ Section for Pharmacology, Institute of Medicine, University of Bergen, Haukeland University Hospital, Norway
}

(Submitted 6 August 2012 - Final revision received 16 October 2012 - Accepted 16 October 2012 - First published online 9 January 2013)

\begin{abstract}
Choline is an essential nutrient that is found in many food sources and plays a critical role in the development of the central nervous system. Animal studies have shown that choline status pre- and postnatally can have long-lasting effects on attention and memory; however, effects in human subjects have not been well studied. The aim of the present study was to examine the association between plasma concentrations of free choline and its related metabolites in children and their neurodevelopment in the Seychelles Child Development Nutrition Study, an ongoing longitudinal study assessing the development of children born to mothers with high fish consumption during pregnancy. Plasma concentrations of free choline, betaine, dimethylglycine (DMG), methionine and homocysteine and specific measures of neurodevelopment were measured in 210 children aged 5 years. The children's plasma free choline concentration ( $9 \cdot 17$ (SD 2.09) $\mu \mathrm{mol} / \mathrm{l})$ was moderately, but significantly, correlated with betaine $(r 0 \cdot 24 ; P=0 \cdot 0006)$, DMG $(r$ 0.15; $P=0 \cdot 03)$, methionine $(r$ 0.24; $P=0.0005)$ and homocysteine $(r 0 \cdot 19 ; P=0 \cdot 006)$ concentrations. Adjusted multiple linear regression revealed that betaine concentrations were positively associated with Preschool Language Scale - total language scores $(\beta=0 \cdot 066 ; P=0 \cdot 04)$, but no other associations were evident. We found no indication that free choline concentration or its metabolites, within the normal physiological range, are associated with neurodevelopmental outcomes in children at 5 years of age. As there is considerable animal evidence suggesting that choline status during development is associated with cognitive outcome, the issue deserves further study in other cohorts.
\end{abstract}

Key words: Choline: Neurodevelopment: Children

Choline functions in several important structural and cell signalling roles, which are integral in the formation of VLDL, phospholipids (phosphatidylcholine and sphingomyelin) and the neurotransmitter acetylcholine $(\mathrm{ACh})^{(1)}$. In addition, choline functions as a methyl donor and is crucial for DNA regulation and repair, protein function and intermediary metabolism. Following cellular uptake, choline is phosphorylated to phosphocholine, or irreversibly oxidised to betaine, which functions to donate methyl groups to homocysteine, producing the essential amino acid methionine ${ }^{(2)}$. Choline can be synthesised endogenously by methylation of phosphatidylethanolamine, a process which occurs primarily in the liver ${ }^{(3)}$, but also occurs in neuronal cells ${ }^{(4)}$. However, de novo synthesis alone is not sufficient to meet human requirements ${ }^{(5)}$. Choline is found naturally in a wide range of foods in the free and esterified form and betaine is also available directly from the diet ${ }^{(6)}$.

A large body of evidence from animal studies suggests that choline supplementation during development improves cognitive and neurological function in offspring ${ }^{(7)}$. Evidence from animal feeding studies suggests a role for choline in hippocampal changes during brain development ${ }^{(8-10)}$. The hippocampus is critical for the development and consolidation of memory, which along with attention, reasoning, language, perception and construction is a crucial component of human intelligence ${ }^{(11)}$. In human subjects, substantial brain development occurs prenatally and continues to be rapid during the first few years of life. Brain development includes

Abbreviations: ACh, acetylcholine; DMG, dimethylglycine; PLS, Preschool Language Scale; tHcy, total homocysteine.

* Corresponding author: Professor J. J. Strain, fax +4428 7012 3023, email jj.strain@ulster.ac.uk 
neurogenesis, axonal and dendritic growth, synaptogenesis, cell death, synaptic pruning, myelination and gliogenesis ${ }^{(12)}$. A number of animal experiments have reported cognitive or other neurological benefits of dietary choline provided either at critical prenatal windows or throughout pregnancy to weaning (for a review, see McCann et al. ${ }^{(7)}$ ). Animal studies have also manipulated intake postnatally and reported beneficial effects in the offspring ${ }^{(13-15)}$. In addition, these studies indicate that in animals the effects of choline supplementation or deficiency during development persist to later in life ${ }^{(7,13,16)}$.

Despite the widely accepted importance of choline in development of the nervous system, the possible role of choline status on neurodevelopment in children has been investigated in few human studies to date. Signore et al. ${ }^{(17)}$ prospectively studied 400 mother-child pairs recruited in Birmingham, Alabama, and reported no association at the age of 5 years between cord blood choline concentration and intelligence quotient scores measured using the Wechsler Preschool and Primary Scale of Intelligence-Revised. However, the present study reported scores well below the national norms on the developmental tests among both mothers and their children, and thereby raised questions about the study's ability to identify beneficial effects of individual nutrients, such as choline, in the face of poor overall nutrition or other environmental variables that might have contributed to the low scores. Wu et $a l .{ }^{(18)}$ found that maternal choline status in the first half of pregnancy was significantly associated with cognitive development among healthy term gestation infants. To date, no study has examined the impact of the child's, rather than the mother's, choline status (and other biomarkers of onecarbon metabolism) on neurodevelopment.

As the brain continues to develop rapidly during childhood, nutrition is likely to continue to have an impact on neurodevelopment in the preschool years ${ }^{(19)}$. Plasma free choline, for example, is a precursor of the endogenous neurotransmitter ACh and disturbances of the ACh system may impair hippocampus-related cognitive and emotional function ${ }^{(20)}$. Also, epigenetic mechanisms, including DNA methylation, function in the neurobiology of cognition ${ }^{(21,22)}$ and provide plausible mechanisms for a role for choline in development. We postulated that choline exposure in early life could affect hippocampal development, thereby affecting memory and intelligence in children. Therefore, we examined the relationship between biological markers of choline status (and other biomarkers of onecarbon metabolism) and neurodevelopment at 5 years of age in the Seychelles Child Development Nutrition Study.

\section{Subjects and methods}

\section{Study population}

Participants were recruited from an ongoing study investigating maternal exposure to methylmercury through fish consumption and developmental outcomes in the Republic of Seychelles, an archipelago of over 100 islands in the Indian Ocean, about $1500 \mathrm{~km}$ off the coast of East Africa. In 2001, we recruited, at their first antenatal visit (gestational age range 14-24 weeks), 300 healthy pregnant women on the island of Mahé to participate in the study. Of those initially recruited, 256 children completed the 5-year evaluation and complete data on choline variables; endpoints and a priori selected covariates were available for 210 children (106 boys and 104 girls).

The present study was conducted according to the guidelines laid down in the Declaration of Helsinki, and all procedures involving human participants were approved by the Institutional Review Boards of the University of Rochester and the Ministry of Health in the Republic of Seychelles. Written informed consent was obtained from all the participants.

\section{Demographic anthropometric and neurodevelopmental assessments}

Birth outcome data, such as birth weight, were obtained from hospital records. When the children were nearing the age 5 years, they were recalled for an evaluation. At the evaluation, mothers completed a questionnaire providing demographic data and the Child Behaviour Checklist (total T-score) $)^{(23)}$ The children completed a test battery, which included anthropometry and a series of cognitive, motor and language tests. Children's height and weight were measured by trained nurses and used to calculate BMI $z$-score based on WHO cut-offs $^{(24)}$. All measuring equipment was calibrated prior to initiation of the study, and regularly throughout the study, by the Seychelles Bureau of Standards.

The neurodevelopmental test battery included the following: Finger Tapping (total taps, dominant and non-dominant hand), the Preschool Language Scale (PLS)-Revised (total language, auditory comprehension and verbal knowledge) $)^{(25)}$, the Woodcock-Johnson Test of Scholastic Achievement (applied problems, letter-word recognition) ${ }^{(26)}$, The Child Behaviour Checklist (total T-score) $)^{(23)}$ and two of three subtests of the Kaufman Brief Intelligence Test (verbal reasoning, matrices) ${ }^{(27)}$. Testing was accomplished by J. H., a Maternal and Child Health Nurse specially trained at the University of Rochester to administer the test battery. All tests were translated to Creole, the language spoken at home in the Republic of Seychelles by the Kreole Institute in Seychelles. All tests were translated from English to Creole and then back-translated. Pilot testing was conducted to verify that test results were in line with the test norms.

\section{Blood sampling and biochemical measurements}

Children's venous non-fasting blood samples were collected in EDTA-containing tubes for plasma separation after completion of the 5-year developmental assessment. Samples were stored in the dark at $4^{\circ} \mathrm{C}$ until separation, which was performed within $0 \cdot 5-2 \cdot 5 \mathrm{~h}$ of the time of sampling. Plasma and whole blood samples were stored (for a maximum of 1 year) at $-70^{\circ} \mathrm{C}$ until batch analysis at the end of the study. Plasma free choline, betaine, dimethylglycine (DMG), total homocysteine (tHcy) and methionine were analysed at the laboratory of Bevital AS (http://www.bevital.no) by liquid chromatography-tandem MS (liquid chromatography-MS/ MS), as described previously ${ }^{(28)}$. 


\section{Covariates}

Analyses controlled for the following covariates known to be associated with child development ${ }^{(29)}$ : birth weight (continuous), child's age at testing (continuous), socio-economic status (the Hollingshead Four-Factor Socioeconomic Status modified for use in the Seychelles; continuous), home environment (the Paediatric Review of Children's Environmental Support and Stimulation continuous), maternal intelligence (measured on the Matrices subtest of the Kaufman Brief Intelligence Test at the child's 19-month evaluation; continuous), sex of the child, the number of nuclear family members living with the child at the time of the 5-year evaluation (living with both parents $v$. other situations) and maternal age (continuous).

\section{Data analysis}

Bivariate relationships among choline, tHcy and related measures and between these measures and neurodevelopmental endpoints were evaluated using correlation coefficients (Pearson or Spearman depending on variable distribution) and scatter plots. $\chi^{2}$ Tests (for categorical variables) and $t$ tests (for continuous variables) were performed to compare covariate values among the 210 subjects with complete data with those of excluded subjects (for whom some covariate data were not available). Analyses were conducted using R 2.12.0 (R Foundation for Statistical Computing) and SAS version 9.2 (SAS Institute, Inc.). All statistical tests were evaluated using a two-sided $P=0.05$ significance level. Nonparametric statistical tests (including the Mann-Whitney test) were used where data could not be normalised (plasma DMG and methionine concentrations) by log-transformation and analysed using parametric tests.

The association of each of the five choline-related measures with each of the ten neurodevelopmental endpoints was estimated using separate multiple linear regression analyses, adjusted for all covariates outlined earlier. As choline metabolism may vary by sex ${ }^{(30)}$, interaction terms between each of the choline measures and sex were included in the models. If the interaction term was not statistically significant, it was excluded and the analysis was rerun. Within each model, we used a two-tailed $\alpha$-level of 0.05 to determine the significance of interactions and independent variable effects.

Regression assumptions were checked for each model. For models in which the assumption of normally distributed errors with constant variance was violated, we log-transformed the dependent variable to stabilise the variance and produce more normally distributed errors. Variance inflation factors were used as a check for collinearity among variables ${ }^{(31)}$. Statistical outliers (defined as observations with standardised residuals greater than 3 in absolute value) and influential points (defined as observations with a Cook's distance larger than $0 \cdot 50)^{(31)}$ were identified for each model and affected models were then run with and without these values. When results differed substantially with the inclusion or exclusion of outliers or influential points, the differences were noted. Although multiple measures of exposures and cognitive outcomes are included, statistical models are not independent and address the same hypothesis and the interpretation of results is guided by prior data reported in previous cohorts ${ }^{(32)}$. The present study, therefore, does not correct for multiple testing, which is overly conservative and suffers from numerous limitations ${ }^{(33,34)}$.

\section{Results}

Relative to the 210 subjects with complete data, excluded subjects (owing to incomplete covariate data, $n$ 46) did not differ significantly in terms of the child's age, sex or birth weight; the mother's age, intelligence or socio-economic status; or the family's home environment. The child's development was assessed at a mean age of 5.61 (SD 0.3) years. In total, $50 \%$ of the subjects were boys. The mean BMI of children at time of testing was $15(\mathrm{SD} 2 \cdot 1) \mathrm{kg} / \mathrm{m}^{2}$. Characteristics of the study cohort, including concentrations of free choline, betaine, DMG and tHcy, are summarised in Table 1. The concentration of free choline and its related metabolites did not differ significantly between boys and girls. However, sex differences were evident in a number of neurodevelopmental endpoints. Boys performed better than girls in Finger Tapping (total, dominant and non-dominant), while girls performed better than boys in the PLS (total language and verbal knowledge) (Table 1). Free choline concentration was significantly correlated with concentration of betaine $(r 0 \cdot 24 ; P=0.0006)$, DMG ( $r$ 0.15; $P=0.03)$, methionine $(r 0.24 ; P=0.0005)$ and tHcy $(r 0 \cdot 19 ; P=0 \cdot 006)$. Betaine concentration was positively correlated with the logarithm of DMG concentration $(r 0 \cdot 28$; $P<0 \cdot 0001)$ and negatively correlated with tHcy concentration $(r-0 \cdot 18 ; P=0 \cdot 01)$. DMG concentration was positively correlated with methionine concentration $(r 0.30 ; P<0.001)$.

The results of multiple linear regression analyses examining the association between choline measures and neurodevelopmental endpoints are presented in Table 2. There was no interaction between the choline measures and sex in any model. The PLS-total language score improved with increasing plasma betaine concentration (i.e. 0.7-point increase in PLS per standard deviation of betaine concentration ('standard deviation of betaine' multiplied by ' $\beta$ value for PLS-total language score')), but there were no other associations present among choline, DMG, methionine or tHcy concentration and any of the endpoints. Results were similar when choline measures were log-transformed.

\section{Discussion}

The major finding from the present study is the lack of significant associations in covariate-adjusted models between choline measures (and other biomarkers of one-carbon metabolism) and various cognitive outcomes in the 5-yearold children in the Seychelles Child Development Nutrition Cohort. We did not find a significant association between the plasma concentration of free choline, or its related metabolites, and children's intelligence assessed by the Kaufman Brief Intelligence Test, a test which measures both verbal and non-verbal intelligence and provides an indication of 
visual perception, cognitive ability and receptive vocabulary. The Woodcock-Johnson Test of Achievement, which assesses the overall level of scholastic achievement, was also non-significantly associated with choline concentration. In addition, we included measures of neurodevelopment that may be more specifically related to choline. For example, the Finger Tapping Test, which provides a measure of fine motor speed, may be relevant in light of reports that postnatal dietary choline supplementation improves gross motor locomotion in mice $^{(35)}$. The PLS and Child Behaviour Checklist provide a more specific assessment of visuospatial and auditory memory and social or emotional responses, domains which may be particularly sensitive to choline ${ }^{(36,37)}$, potentially owing to the influence of ACh on hippocampal plasticity ${ }^{(20)}$. Nevertheless, we did not find any consistent relationships between the endpoints measured and the plasma concentration of choline, DMG, methionine or tHcy. However, plasma betaine concentration was positively associated with the PLS-total language score. A previous intervention study in healthy elderly adults reported a positive effect of betaine on memory performance, which the authors speculated was explained by the greater availability of choline metabolites for synthesis of ACh and structural phospholipids, such as phosphatidylcholine and sphingomyelin ${ }^{(38)}$. Such a mechanism is also plausible in children, particularly as the early years are a time of rapid brain growth, with the peak time for development between 5 months gestation and 4 years of age ${ }^{(39)}$. Albeit scientifically plausible, the present finding that the PLS-total language score was significantly associated with betaine requires confirmation in future research, as it may be owing to chance.

To our knowledge, the present study is the first to examine the relationship between the plasma concentration of choline and other biomarkers of one-carbon metabolism and concomitant cognitive performance in children. Animal studies, however, have consistently shown a cause-and-effect relationship between postnatal choline intake (and other biomarkers of one-carbon metabolism) and subsequent performance in offspring $^{(7)}$, with beneficial effects reported to be long term and evident in adulthood and old age ${ }^{(13)}$. The majority of research investigating choline intake and performance has been undertaken in animal models, specifically in rodents ${ }^{(7)}$. The growth and development of the rat and human brain progress at different rates, making direct extrapolation of animal data to human subjects difficult. However, similar to the rat, it has been reported that a large proportion $(80 \%)$ of the human brain growth spurt is postnatal ${ }^{(40)}$. This observation, together with the evidence that neural plasticity in response

Table 1. Summary statistics for predictors, cognitive endpoints and covariates in 5 year-old Seychellois children (Mean values and standard deviations)

\begin{tabular}{|c|c|c|c|c|c|c|c|}
\hline & \multicolumn{2}{|c|}{ All $(n 210)$} & \multicolumn{2}{|c|}{ Boys ( $n$ 106) } & \multicolumn{2}{|c|}{ Girls (n 104) } & \multirow[b]{2}{*}{$P^{*}$} \\
\hline & Mean & SD & Mean & SD & Mean & SD & \\
\hline \multicolumn{8}{|l|}{ Predictors } \\
\hline Free choline $(\mu \mathrm{mol} / \mathrm{l})$ & $9 \cdot 17$ & 2.09 & $9 \cdot 21$ & 1.92 & $9 \cdot 13$ & $2 \cdot 30$ & 0.780 \\
\hline Betaine $(\mu \mathrm{mol} / \mathrm{l})$ & $45 \cdot 80$ & $10 \cdot 80$ & 44.4 & $10 \cdot 8$ & $47 \cdot 10$ & $10 \cdot 7$ & 0.070 \\
\hline Dimethylglycine $(\mu \mathrm{mol} / \mathrm{l})$ & 4.83 & $2 \cdot 62$ & 4.94 & 2.65 & 4.70 & $2 \cdot 60$ & 0.500 \\
\hline Met $(\mu \mathrm{mol} / \mathrm{l})$ & $25 \cdot 10$ & $7 \cdot 70$ & $25 \cdot 50$ & 8.60 & 24.80 & $6 \cdot 80$ & 0.970 \\
\hline Homocysteine $(\mu \mathrm{mol} / \mathrm{l})$ & $6 \cdot 14$ & 1.44 & $6 \cdot 10$ & 1.40 & $6 \cdot 20$ & 1.50 & 0.460 \\
\hline \multicolumn{8}{|l|}{ Endpoints } \\
\hline \multicolumn{8}{|l|}{ Finger Tapping } \\
\hline Total & 44.50 & $9 \cdot 80$ & 46.60 & $9 \cdot 50$ & $42 \cdot 40$ & $9 \cdot 70$ & 0.002 \\
\hline Dominant hand & 23.40 & $5 \cdot 70$ & 24.80 & $5 \cdot 20$ & 21.90 & $5 \cdot 90$ & 0.0002 \\
\hline Non-dominant hand & $21 \cdot 20$ & 4.90 & 21.80 & 4.90 & $20 \cdot 50$ & $4 \cdot 80$ & 0.050 \\
\hline \multicolumn{8}{|l|}{ PLS } \\
\hline Total language & $118 \cdot 70$ & 5.40 & $117 \cdot 90$ & $5 \cdot 60$ & $119 \cdot 50$ & 4.90 & 0.050 \\
\hline Auditory comprehension & 55.60 & $2 \cdot 70$ & 55.40 & $2 \cdot 90$ & $55 \cdot 80$ & $2 \cdot 50$ & 0.420 \\
\hline Verbal knowledge & 63.10 & $3 \cdot 30$ & 62.50 & 3.40 & 63.70 & 3.00 & 0.006 \\
\hline \multicolumn{8}{|l|}{ WJ } \\
\hline Applied problems & $15 \cdot 10$ & $4 \cdot 10$ & 14.80 & 4.20 & $15 \cdot 40$ & $4 \cdot 10$ & 0.250 \\
\hline Letter-word recognition & $11 \cdot 20$ & $5 \cdot 90$ & 10.50 & $5 \cdot 70$ & 11.90 & $6 \cdot 10$ & 0.090 \\
\hline $\mathrm{CBCL}$ & 59.40 & 8.40 & 60.00 & 8.90 & $58 \cdot 80$ & 7.90 & 0.290 \\
\hline \multicolumn{8}{|l|}{ K-BIT } \\
\hline Verbal reasoning & $11 \cdot 70$ & $2 \cdot 80$ & 11.40 & $2 \cdot 80$ & $12 \cdot 10$ & $2 \cdot 80$ & 0.080 \\
\hline Matrices & $7 \cdot 70$ & 1.20 & $7 \cdot 70$ & $1 \cdot 30$ & $7 \cdot 75$ & $1 \cdot 20$ & 0.970 \\
\hline \multicolumn{8}{|l|}{ Covariates } \\
\hline Birth weight $(\mathrm{g})$ & 3238 & 492 & 3335 & 487 & 3138 & 480 & 0.004 \\
\hline Child's age at testing (years) & 5.60 & 0.30 & $5 \cdot 60$ & 0.30 & 5.60 & 0.80 & 0.330 \\
\hline Child's BMI at testing $\left(\mathrm{kg} / \mathrm{m}^{2}\right)$ & $15 \cdot 00$ & 2.05 & $15 \cdot 10$ & 1.90 & 14.90 & $2 \cdot 20$ & 0.490 \\
\hline BMI $z$-score & -0.34 & 1.26 & -0.27 & 1.23 & -0.42 & 1.28 & 0.410 \\
\hline Socio-economic status & $31 \cdot 20$ & $10 \cdot 90$ & 32.50 & 11.40 & $29 \cdot 80$ & $10 \cdot 20$ & $0 \cdot 100$ \\
\hline PROCESS & $152 \cdot 00$ & $15 \cdot 00$ & 152.00 & 15.00 & 152.00 & 15.00 & 0.750 \\
\hline Maternal K-BIT (matrices) & $86 \cdot 30$ & $13 \cdot 60$ & $86 \cdot 20$ & 14.40 & $86 \cdot 30$ & 12.90 & 0.950 \\
\hline Maternal age at child's birth (years) & 27.90 & $6 \cdot 10$ & $28 \cdot 10$ & 6.20 & 27.60 & 5.90 & 0.630 \\
\hline
\end{tabular}

PLS, Preschool Language Scale; WJ, Woodcock-Johnson; CBCL, Child Behaviour Checklist; K-BIT, Kaufman Brief Intelligence Test; PROCESS, Paediatric Review of Children's Environmental Support and Stimulation.

${ }^{*}$ Comparison between boys and girls using $t$ test or Mann-Whitney test as appropriate. 
Table 2. Associations between choline and its related metabolites and neurodevelopmental endpoints in 5 year-old Seychellois children

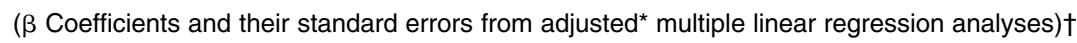

\begin{tabular}{|c|c|c|c|c|c|c|c|c|c|c|}
\hline & \multicolumn{2}{|c|}{ Free choline } & \multicolumn{2}{|c|}{ Betaine } & \multicolumn{2}{|c|}{ Dimethylglycine } & \multicolumn{2}{|c|}{ Met } & \multicolumn{2}{|c|}{ Homocysteine } \\
\hline & $\beta$ & SE & $\beta$ & SE & $\beta$ & SE & $\beta$ & SE & $\beta$ & SE \\
\hline \multicolumn{11}{|l|}{ Finger Tapping } \\
\hline Total & 0.310 & 0.330 & -0.056 & 0.063 & 0.042 & 0.260 & -0.010 & 0.090 & 0.094 & 0.470 \\
\hline$R^{2}$ & \multicolumn{2}{|c|}{0.06} & \multicolumn{2}{|c|}{0.06} & \multicolumn{2}{|c|}{0.06} & \multicolumn{2}{|c|}{0.06} & \multicolumn{2}{|c|}{0.06} \\
\hline$P$ & \multicolumn{2}{|c|}{$0 \cdot 14$} & \multicolumn{2}{|c|}{0.14} & \multicolumn{2}{|c|}{0.18} & \multicolumn{2}{|c|}{0.18} & \multicolumn{2}{|c|}{0.18} \\
\hline Dominant & 0.180 & 0.190 & -0.080 & 0.036 & 0.029 & 0.150 & -0.0019 & 0.051 & -0.021 & 0.270 \\
\hline$R^{2}$ & \multicolumn{2}{|c|}{0.09} & \multirow{2}{*}{\multicolumn{2}{|c|}{$\begin{array}{r}0.09 \\
0.02\end{array}$}} & \multicolumn{2}{|c|}{0.09} & \multirow{2}{*}{\multicolumn{2}{|c|}{0.09}} & \multicolumn{2}{|c|}{0.09} \\
\hline$P$ & \multicolumn{2}{|c|}{0.02} & & & \multicolumn{2}{|c|}{0.02} & & & & \\
\hline Non-dominant & 0.130 & 0.170 & -0.048 & 0.032 & 0.014 & 0.130 & -0.009 & 0.040 & 0.096 & 0.240 \\
\hline$R^{2}$ & & & & & & & & & & \\
\hline$P$ & & & & & & & & & & \\
\hline PLS & & & & & & & & & & \\
\hline Total language & 0.007 & 0.170 & $0.066 \ddagger$ & 0.032 & 0.017 & 0.130 & -0.007 & 0.045 & -0.360 & 0.240 \\
\hline$R^{2}$ & & & 0 & & & & & & & \\
\hline$P$ & $<0$ & & $<0$ & & $<0$ & & & & $<0$ & \\
\hline Auditory comprehension & 0.030 & 0.080 & 0.029 & 0.016 & -0.035 & 0.067 & -0.010 & 0.023 & -0.130 & 0.120 \\
\hline$R^{2}$ & 0 & & 0 & & & & & & & \\
\hline$P$ & $<0$ & & $<0$ & & & & & & $<0$ & \\
\hline Verbal knowledge & -0.030 & 0.10 & 0.038 & 0.020 & 0.082 & 0.083 & 0.0029 & 0.028 & -0.230 & 0.150 \\
\hline$R^{2}$ & 0 & & 0 & & & & & & & \\
\hline$P$ & 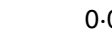 & & $<0$ & & & & & & $<0$ & \\
\hline WJ & & & & & & & & & & \\
\hline Applied problems & -0.210 & $0 \cdot 12$ & 0.018 & 0.023 & -0.12 & 0.094 & -0.019 & 0.032 & -0.220 & 0.170 \\
\hline$R^{2}$ & & & 0 & & & & & & & \\
\hline$P$ & $<0$ & & $<0$ & & $<0$ & & & & $<0$ & \\
\hline Letter-word recognition & 0.035 & 0.160 & 0.029 & 0.030 & -0.083 & 0.130 & 0.013 & 0.043 & -0.140 & 0.230 \\
\hline$R^{2}$ & 0 & & 0 & & & & & & & \\
\hline$P$ & $<0$ & & $<0$ & & $<0$ & & & & $<0$ & \\
\hline CBCL & 0.170 & 0.270 & -0.040 & 0.051 & -0.260 & 0.210 & -0.076 & 0.072 & 0.650 & 0.380 \\
\hline$R^{2}$ & 0 & & 0 & & & & & & & \\
\hline$P$ & $<0$ & & $<0$ & & & & & & $<0$ & \\
\hline K-BIT & & & & & & & & & & \\
\hline Verbal reasoning & 0.072 & 0.080 & -0.0009 & 0.017 & -0.087 & 0.070 & -0.008 & 0.024 & 0.150 & 0.130 \\
\hline$R^{2}$ & 0 & & 0 & & & & & & & \\
\hline$P$ & $<0$ & & $<0$ & & $<0$ & & & & $<0$ & \\
\hline Matrices & 0.044 & 0.040 & 0.007 & 0.008 & 0.030 & 0.032 & -0.008 & 0.011 & 0.084 & 0.060 \\
\hline$R^{2}$ & 0 & & 0 . & & & & & & 0 & \\
\hline$P$ & & & $0 . c$ & & & & & & & \\
\hline
\end{tabular}

PLS, Preschool Language Scale; WJ, Woodcock-Johnson; CBCL, Child Behaviour Checklist; K-BIT, Kaufman Brief Intelligence Test.

${ }^{*}$ Adjusted for birth weight, child's age at testing, socio-economic status, home environment, maternal intelligence, sex of the child, the number of nuclear family members living with the child and maternal age.

†For all models, $n 210$ and $\mathrm{df}=200$.

$\ddagger$ Significant association $(P=0.04)$.

to learning continues throughout childhood, would suggest that requirements for brain-related nutrients, including choline, would be important in early childhood ${ }^{(19)}$. The essentiality of nutrients will be related to the timing of their delivery, compared with the critical periods during brain development. However, unlike the prenatal period, the windows of exposure for brain development during the pre-school years are relatively broad ${ }^{(41)}$, while, furthermore, the capacity for plasticity within the human brain may allow it to compensate for fluctuations in nutritional status.

Choline circulates in a bound form, mostly in the form of phosphatidylcholine, or in a free form initially reported as a likely mechanism supplying choline to the brain ${ }^{(42)}$. Although an accepted and often used biomarker of choline status, plasma free choline represents only a fraction of the total choline pool ${ }^{(43)}$ and may be a poor marker of ACh synthesis and status in the brain ${ }^{(44)}$. Indeed, another study that reported a positive association between betaine status and memory also observed no association with plasma free choline concentration $^{(38)}$. Our lack of association may also be attributed to the high plasma choline concentration (status) of the children in the Seychelles. A previous study only observed a relationship between plasma choline concentration and leucocyte ACh concentration in children who had low choline status ${ }^{(45)}$; no relationship was evident in children who had plasma concentrations of choline, betaine and DMG, similar to those reported in the present analysis. The lack of significant associations may also be owing to the small sample size of the present study.

The present study has a number of strengths. The cohort of 300 mothers initially recruited to the present study represented one-fifth of total annual deliveries in the Seychelles and $75 \%$ of all women booking at antenatal clinics during the enrolment period, and was therefore considered to be a representative sample of the population ${ }^{(46)}$. In addition, the children were sampled and tested early in childhood within a period 
of significant brain development, and the test battery used specific and reproducible measures of pre-school neurological function. Extensive data on additional factors that influence child development were also collected and controlled for in the present analysis. Furthermore, choline, betaine, DMG and tHcy were assessed using a sensitive method based on liquid chromatography-MS/MS ${ }^{(28)}$, and plasma free choline concentrations were in keeping with values reported previously in US children $^{(17,45)}$. However, the study also has limitations. The cohort size was not adequate to examine interactions (between choline and the other biomarkers of one-carbon metabolism on neurodevelopmental endpoints) and other unmeasured covariates, such as folate and vitamin $\mathrm{B}_{12}$, which may have been significant. In addition, the critical period, if any, for human postnatal development with respect to choline may not correspond to 5 years of age. As nonfasting samples were collected from the children, plasma choline concentrations may have been sensitive to recent dietary intakes.

In summary, we found few significant associations between the concentration of free choline (within the normal physiological range for children), or its metabolites, and cognitive outcome in children at 5 years of age. However, the experimental evidence suggesting that choline status is positively associated with cognitive outcome in animals supplemented with choline in the postnatal period suggests that this issue needs further investigation.

\section{Acknowledgements}

We thank all the women and children who participated in the study and the nursing staff in the Seychelles for their assistance with data collection. The present study was supported by the US National Institute of Environmental Health Sciences, National Institutes of Health (R01-ES010219, R01-ES015578, P30-ES001247 and T32-ES007271), the European Union (Sixth Framework Programme; PHIME; FOOD-CT-2006016253) and by the Government of Seychelles. The contents reflect only the authors' views; the European Union is not liable for any use that may be made of the information. The authors' responsibilities were as follows: J. M. W. W., M. P. B., E. M. Mc. S. and J. J. S. were involved in the hypothesis generation, organisation of the study, statistical analysis, and data interpretation; E. v. W., R. W. K. and S. W. T. assisted in the statistical analysis and data interpretation; P. W. D., G. J. M., G. E. W. and C. F. S. contributed to the study design and implementation; M. S. M., A. J. Mc. A. and J. H. were involved in the sample analysis and data interpretation; and P. M. U. contributed to the sample analysis; all authors contributed to the manuscript preparation. No author had any conflict of interest.

\section{References}

1. Ueland PM (2011) Choline and betaine in health and disease. $J$ Inherit Metab Dis 34, 3-15.
2. Zeisel SH, Mar MH, Howe JC, et al. (2003) Concentrations of choline-containing compounds and betaine in common foods. J Nutr 133, 1302-1307.

3. Ridgway ND, Yao Z \& Vance DE (1989) Phosphatidylethanolamine levels and regulation of phosphatidylethanolamine N-methyltransferase. J Biol Chem 264, 1203-1207.

4. Blusztajn JK, Liscovitch M \& Richardson UI (1987) Synthesis of acetylcholine from choline derived from phosphatidylcholine in a human neuronal cell line. Proc Natl Acad Sci U S A 84, 5474-5477.

5. Zeisel SH \& da Costa KA (2009) Choline: an essential nutrient for public health. Nutr Rev 67, 615-623.

6. USDA (2008) US Department of Agriculture Database for the Choline Content of Common Foods, Release Two. Beltsville, MD: US Department of Agriculture.

7. McCann JC, Hudes M \& Ames BN (2006) An overview of evidence for a causal relationship between dietary availability of choline during development and cognitive function in offspring. Neurosci Biobehav Rev 30, 696-712.

8. Albright CD, Mar MH, Friedrich CB, et al. (2001) Maternal choline availability alters the localization of p15Ink4B and p27Kip1 cyclin-dependent kinase inhibitors in the developing fetal rat brain hippocampus. Dev Neurosci 23, 100-106.

9. Albright CD, Tsai AY, Mar MH, et al. (1998) Choline availability modulates the expression of TGFbeta1 and cytoskeletal proteins in the hippocampus of developing rat brain. Neurochem Res 23, 751-758.

10. Wong-Goodrich SJ, Glenn MJ, Mellott TJ, et al. (2008) Spatial memory and hippocampal plasticity are differentially sensitive to the availability of choline in adulthood as a function of choline supply in utero. Brain Res 1237, 153-166.

11. Baron I (2004) Neuropsychological Evaluation of the Child. New York, NY: Oxford University Press.

12. Grantham-McGregor S, Cheung YB, Cueto S, et al. (2007) Developmental potential in the first 5 years for children in developing countries. Lancet 369, 60-70.

13. Meck WH, Williams CL, Cermak JM, et al. (2007) Developmental periods of choline sensitivity provide an ontogenetic mechanism for regulating memory capacity and age-related dementia. Front Integr Neurosci 1, 7.

14. Ryan SH, Williams JK \& Thomas JD (2008) Choline supplementation attenuates learning deficits associated with neonatal alcohol exposure in the rat: effects of varying the timing of choline administration. Brain Res 1237, 91-100.

15. Ward BC, Kolodny NH, Nag N, et al. (2009) Neurochemical changes in a mouse model of Rett syndrome: changes over time and in response to perinatal choline nutritional supplementation. J Neurochem 108, 361-371.

16. Zeisel SH (2006) The fetal origins of memory: the role of dietary choline in optimal brain development. $J$ Pediatr 149, S131-S136.

17. Signore C, Ueland PM, Troendle J, et al. (2008) Choline concentrations in human maternal and cord blood and intelligence at 5 y of age. Am J Clin Nutr 87, 896-902.

18. Wu BTF, Dyer RA, King DJ, et al. (2012) Early second trimester maternal plasma choline and betaine are related to measures of early cognitive development in term infants. PLoS One 7, e43448.

19. Rosales FJ, Reznick JS \& Zeisel SH (2009) Understanding the role of nutrition in the brain and behavioral development of toddlers and preschool children: identifying and addressing methodological barriers. Nutr Neurosci 12, 190-202.

20. Busche A, Bagorda A, Lehmann K, et al. (2006) The maturation of the acetylcholine system in the dentate gyrus of gerbils (Meriones unguiculatus) is affected by epigenetic factors. J Neural Transm 113, 113-124. 
21. Sweatt JD (2010) Neuroscience. Epigenetics and cognitive aging. Science 328, 701-702.

22. Roth TL, Roth ED \& Sweatt JD (2010) Epigenetic regulation of genes in learning and memory. Essays Biochem $\mathbf{4 8}$, $263-274$

23. Achenbach TM (1991) Manual for the Child Behavior Checklist and 1991 Child Behavior Profile. Burlington: Department of Psychiatry, University of Vermont.

24. de Onis M, Onyango AW, Borghi E, et al. (2007) Development of a WHO growth reference for school-aged children and adolescents. Bull World Health Organ 85, 660-667.

25. Zimmerman I, Steiner V \& Pond RE (1979) Preschool Language Scale. Columbus, $\mathrm{OH}$ : Charles Merrill.

26. Woodcock RW \& Johnson MB (1989) Woodcock-Johnson Psycho-educational Battery - Revised. Allen, TX: DLM Teaching Resources.

27. Kaufman AS \& Kaufman NL (2004) Kaufman Brief Intelligence Test (KBIT-2), 2nd ed. Bloomington, MN: Pearson, Inc.

28. Holm PI, Ueland PM, Kvalheim G, et al. (2003) Determination of choline, betaine, and dimethylglycine in plasma by a high-throughput method based on normal-phase chromatography-tandem mass spectrometry. Clin Chem 49. 286-294.

29. Davidson PW, Myers GJ, Cox C, et al. (1998) Effects of prenatal and postnatal methylmercury exposure from fish consumption on neurodevelopment: outcomes at 66 months of age in the Seychelles Child Development Study. JAMA 280, 701-707.

30. Chew TW, Jiang X, Yan J, et al. (2011) Folate intake, MTHFR genotype, and sex modulate choline metabolism in mice. J Nutr 141, 1475-1481.

31. Weisberg S (2005) Applied Linear Regression. New York, NY: Wiley.

32. Strain JJ, Davidson PW, Thurston SW, et al. (2012) Maternal PUFA status but not prenatal methylmercury exposure is associated with children's language functions at age five years in the Seychelles. J Nutr 142, 1943-1949.

33. Glantz SA (2002) A Primer of Biostatistics. New York, NY: McGraw-Hill.

34. Perneger TV (1998) What's wrong with Bonferroni adjustments? BMJ 316, 1236-1238.
35. Nag N \& Berger-Sweeney JE (2007) Postnatal dietary choline supplementation alters behavior in a mouse model of Rett syndrome. Neurobiol Dis 26, 473-480.

36. Meck WH, Smith RA \& Williams CL (1988) Pre- and postnatal choline supplementation produces long-term facilitation of spatial memory. Dev Psychobiol 21, 339-353.

37. Cheng RK, MacDonald CJ, Williams CL, et al. (2008) Prenatal choline supplementation alters the timing, emotion, and memory performance (TEMP) of adult male and female rats as indexed by differential reinforcement of low-rate schedule behavior. Learn Mem 15, 153-162.

38. Eussen SJ, Ueland PM, Clarke R, et al. (2007) The association of betaine, homocysteine and related metabolites with cognitive function in Dutch elderly people. Br J Nutr 98, 960-968.

39. Shen EY, Wu KH, Lin MF, et al. (2010) Study of brain growth in children - a new approach to volume measurements using MRI-reconstructed 3D neuroimaging. Childs Nerv Syst 26, 1619-1623

40. Dobbing J \& Sands J (1973) Quantitative growth and development of human brain. Arch Dis Child 48, 757-767.

41. Rosales FJ \& Zeisel SH (2008) Perspectives from the symposium: the role of nutrition in infant and toddler brain and behavioral development. Nutr Neurosci 11, 135-143.

42. Klein J, Koppen A, Loffelholz K, et al. (1992) Uptake and metabolism of choline by rat brain after acute choline administration. J Neurochem 58, 870-876.

43. Zeisel SH (2004) Nutritional importance of choline for brain development. J Am Coll Nutr 23, 621S-626S.

44. Amenta F \& Tayebati SK (2008) Pathways of acetylcholine synthesis, transport and release as targets for treatment of adult-onset cognitive dysfunction. Curr Med Chem 15, 488-498.

45. Innis SM, Davidson AG, Bay BN, et al. (2011) Plasma choline depletion is associated with decreased peripheral blood leukocyte acetylcholine in children with cystic fibrosis. $\mathrm{Am}$ J Clin Nutr 93, 564-568.

46. Bonham MP, Duffy EM, Robson PJ, et al. (2009) Contribution of fish to intakes of micronutrients important for fetal development: a dietary survey of pregnant women in the Republic of Seychelles. Public Health Nutr 12, 1312-1320. 